\title{
El funcionamiento y la \\ dinámica interna de las \\ salas de enfermos del \\ Hospital Real de San Miguel \\ de Belén de Guadalajara, \\ 1797-1799
}

\section{Hugo Humberto Salas Pelayo ${ }^{1}$ hugohsalas@hotmail.com}

Operation and dynamics of the ill rooms of the Hospital Real de San Miguel de Belén of Guadalajara between 1797-1799

\section{Resumen}

Entre 1797-1799 las salas de enfermos del Hospital Real de San Miguel de Belén, eran administradas por la orden de Nuestra Señora de Belén conocidos como los betlemitas. En el periodo comprendido entre 1797-1798, en la Nueva España y Guadalajara, se presentó una epidemia de viruela. En el recinto se atendió a los virulentos a la par de continuar brindando atención a convalecientes que ingresaban con otros padecimientos. A partir del análisis de los registros hospitalarios de la época, estas líneas examinan la atención y distribución de enfermos en salas de un recinto que responde a las necesidades sociales del momento contando con la capacidad de brindar atención y resguardo a los pobres y enfermos que requieren ayuda.

Palabras clave: epidemia de viruela, enfermos, Hospital de Belén, registros hospitalarios, betlemitas.

\section{Abstract}

Between 1797-1799 the rooms for the ill in the Hospital Real de San Miguel de Belén, were run by the order of Our Lady of Bethlehem known as the Bethlemitas. In that period of time, in the New Spain and in Guadalajara, an epidemic of smallpox occurred. Thus, this medical institution had to provide assistance to both the virulent and convalescent patients with other diseases. Based on the analysis of the hospital records at that time, we can examine the procedures used for the care and distribution of patients in the hospital rooms as well as the social needs of the moment, paying attention to the capacity to provide care and shelter to the poor and sick that required assistance. Key words: epidemic of smallpox, ill, Hospital de Belén, Hospital records, bethlemitas. Doctorado en Historia, Universidad Michoacana de San Nicolás de Hidalgo, México Ciudad Universitaria, Área de Institutos, Edificio C-1, Av. Fco. J. Múgica s/n, Col. Villa Universidad 58030, Morelia, Michoacán, México. 


\section{Introducción ${ }^{2}$}

Las presentes líneas forman parte de una investigación sobre la historia hospitalaria de Guadalajara, ${ }^{3}$ cuya finalidad es mostrar un panorama sobre la distribución de enfermos en las salas del Hospital Real de San Miguel de Belén (actual Hospital Civil de Guadalajara Fray Antonio Alcalde) durante el periodo comprendido entre 1797 y 1799, etapa en la que se presentó en Nueva España y en Guadalajara una epidemia de viruela. En el nosocomio se recibió y atendió a los enfermos virulentos y convalecientes que ingresaban con diferentes padecimientos. A partir del análisis de los registros hospitalarios se examina la distribución de enfermos en las diferentes salas, se presentan las estimaciones del número de ingresos y salidas, así como las acciones cotidianas que, desde la asistencia social y religiosa, desempeñaban los betlemitas encargados de su administración.

Nuestro eje de estudio se basa en la captura y sistematización de los registros hospitalarios consignados en los libros de entradas y salidas de enfermos del Hospital Real de San Miguel de Belén ${ }^{4}$, fuente que hace referencia a las estadísticas de los convalecientes que ingresaban al nosocomio. Según Lilia Oliver (1997), los registros pueden ayudar a reconstruir parte de la historia hospitalaria de la ciudad:

La información anotada en estos registros constituye una valiosa fuente [...] para la historia del propio hospital, para el análisis social y para el análisis demográfico. Sobre el primer tema la fuente nos permite conocer la distribución de los enfermos en el hospital por salas, el número de ingresos diarios, por mes, por año y los periodos de internamiento, entre otras cosas [...] una característica de este tipo de fuentes, contrario a lo que pudiera pensarse, es que no pueden ser utilizadas para hacer estudios estadísticos sobre enfermedades [...] Sin embargo, como mencionamos antes, excepcionalmente se puede encontrar información relacionada con las enfermedades que permita profundizar en la historia del hospital. Para nuestro caso, cuando se trataba de enfermos de lepra (lazarinos), de rabia, de algún problema

\footnotetext{
A la memoria de mi padre.

Tesis en curso para el Doctorado de Historia de la Universidad Michoacana de San Nicolás de Hidalgo, Morelia. Libros de entradas y salidas de enfermos del Hospital Real de San Miguel de Belén, localizados en el AHJ.
} 
mental (locos, simples, fatuos, etc.), o de enfermedades epidémicas

(apestados, virulentos, etc.) normalmente se especificaba (p. 458).

Esta fuente, como menciona Oliver, permite plantear un estudio sobre la historia hospitalaria de la ciudad a través de ciertas enfermedades. En este caso, la viruela y otros padecimientos. Más que pretender realizar un estudio estadístico sobre las enfermedades, se mostrarán las problemáticas que presentaban las salas, entre ellas las "de fiebres" y el resto de las enfermerías, tanto de hombres como de mujeres, frente a la presencia de padecimientos como la viruela, así como el tiempo que los pacientes permanecieron internados con éste y otros males.

Los registros poseen valiosa información personal de cada enfermo que ingresaba y las anotaciones eran realizadas por un religioso betlemita. Se consigna la fecha de ingreso, salida o muerte; el nombre del enfermo, el de los padres en caso de ser soltero, o del cónyuge si era casado o viudo; se registra la calidad, la edad, el estado civil, el lugar de origen, el nombre de la sala y número de cama y, en ciertos periodos, el nombre de la enfermedad, entre otros datos. ${ }^{5}$

La captura y sistematización de los registros, así como las reflexiones que surjan de su análisis, corresponde a este lapso de tres años (17971799). Se aborda este trienio porque los registros del nosocomio señalan la presencia de enfermos de viruela y otros padecimientos, lo cual permite realizar una serie de planteamientos sobre la distribución por salas y las variaciones que se presentan entre un año regular y uno de sobremortalidad.

Con los datos de las salas de enfermos se indagará sobre el tipo de asistencia que se les brindó, los cambios que podemos percibir y los padecimientos más comunes y relevantes. Las variables ayudarán a examinar los siguientes ejes: la concepción que se tiene del hospital y de cada sala, de acuerdo con lo establecido en las Constituciones de los betlemitas y si se respetaba; el impacto del edificio en el número de personas ingresadas, así como los cambios, pautas y dinámicas que permitan entender de forma general la práctica hospitalaria. Sin embargo, antes es necesario delinear el entorno histórico de finales del siglo XVIII que rodea al hospital, sus salas y actores. manera formal y la serie documental está completa, con un estimado de 9149 registros capturados de forma nominal para los tres años. 


\section{La ciudad a finales del siglo XVIII:}

el entorno social

Guadalajara, como principal centro administrativo del Occidente de la Nueva España, agrupó los máximos órganos del gobierno político, religioso, cultural y económico. Fue sede de Ayuntamiento, Real Audiencia, Obispado, Caja Real, Intendencia, Universidad, Consulado y Hospital, lo que definió a la ciudad como centro político financiero, mercado, núcleo de distribución comercial y capital intelectual (Gálvez, 1996, p. 162). Aunque también se caracterizó por presentar serios problemas sociales como la insuficiencia del abasto de alimentos para toda su población y la que constantemente llegaba a la ciudad en forma de migración temporal o permanente, presencia constante de epidemias y falta de higiene, entre otros, sin olvidar que durante la segunda mitad del siglo XVIII la Nueva España tuvo un crecimiento demográfico constante. ${ }^{6}$ De acuerdo con ciertas estimaciones, la población pasó de un aproximado de 22163 habitantes en 1777 (Gálvez, 1996, p. 95), a 24249 para 1792 (Menéndez, 1980, p. 161).

Esta relativa dinámica demográfica, además de explicarse como producto de la migración desde zonas rurales, hace referencia a las posibilidades que ofrecía la vida urbana y a los mayores problemas de pobreza que generaba el medio rural. De esta forma, a pesar de que Guadalajara estuvo entre las ciudades más pobladas del virreinato, sólo por debajo de la ciudad de México, Puebla y Guanajuato, su crecimiento demográfico recrudeció los problemas sociales y de higiene en la ciudad.

Uno de los factores más importantes que explican esa migración rural a la ciudad fue la problemática agrícola y diferentes enfermedades oportunistas y epidémicas que se presentaron durante el llamado "año del hambre" de 1785-1786, que se caracterizó por ser uno de los periodos de sobremortalidad más letales del siglo XVIII. También hubo otros episodios. como las epidemias de viruela (1780, 1797-1798, etc.), que de igual forma se presentaron en toda la Nueva España.

El contexto de enfermedad y muerte del año del hambre y demás epidemias en la segunda mitad del siglo xviII mostró la vulnerabilidad de la población y de la ciudad ante los problemas de enfermedad. Sin duda las circunstancias obligaron a la construcción de un nuevo hospital con mayor capacidad y un camposanto anexo que respondieran a los problemas Los estudios de Eric Van Young y Ramón María Serrera demostraron este crecimiento demográfico de la ciudad y su región durante la segunda mitad del siglo XVIII: Van Young, 1989, pp. 285-305 y Serrera, 1991, pp. 36-51. 
sociales del momento. De ahí surgió la necesidad por impulsar un nuevo establecimiento hospitalario, cuyo principal artífice fue el Obispo de Guadalajara Fray Antonio Alcalde (1771-1792), quien contribuyó de manera significativa para la construcción del nuevo Hospital de San Miguel, también conocido como la Nueva Fábrica de Belén (Oliver, 1992, pp. 223-236).

\section{El Hospital Real de San Miguel de Belén}

Existen investigaciones que abordan la historia de la institución ${ }^{7}$ y no es nuestra intención regresar a esos planteamientos, sino esbozar sólo algunas ideas claves sobre el concepto del hospital bajo el cual se fundó, para lo cual es necesario retomar algunos criterios cuyos orígenes se remontan a la Edad Media y que persistieron hasta finales del siglo XVIII, cuando se construyó en Guadalajara la Nueva Fábrica de Belén. El primer hospital había sido fundado en 1581 (Oliver, 1992, p. 51) y se estableció, al igual que todos los de su época, respondiendo a la concepción cristiana de la caridad (Muriel, 1990, t. I, pp. 10-12). Este principio de ayuda al pobre y al enfermo era también un medio de salvación del alma (Rosen, 1985, p. 318). Por eso los hospitales, hospicios y obras asistenciales fueron instituciones religiosas: "en esencia, los hospitales eran casas religiosas en las que el personal de enfermería se había reunido como una comunidad vocacional bajo una orden religiosa" (Rosen, 1985, p. 325). Para Muriel, el hospital era

una casa donde se recibía a todos los necesitados. Por lo tanto, en unas ocasiones eran hospitales de pobres, en otras hospederías para peregrinos, bien orfelinatos o asilo para enfermos [...] la caridad lo que pretendía era dar auxilio a todos los necesitados, ya fuesen éstos los pobres, los enfermos, los peregrinos que dejaban sus hogares para visitar los grandes santuarios de la cristiandad, o bien los pequeños huérfanos. Ideal era hospedarlos a todos, para que sus distintas necesidades fuesen satisfechas, pero de modo primordial las necesidades espirituales (Muriel, 1990, t. I, pp. 12-13).

Éstos son la óptica religiosa y el principio de caridad cristiana impulsados a través del sistema hospitalario por la Corona española en el mundo novohispano, los cuales se manifestaron a través de las disposiciones y demás ordenanzas reales del momento, como la emitida por el Rey Carlos I en 1541, que señala "que con especial cuidado provean que en todos

7 Muriel, 1990, t. I, pp. 275-279; Oliver, 1992; Gálvez, 1996, pp. 155-162. 
los pueblos de españoles e indios de sus provincias y jurisdicciones se funden hospitales donde sean curados los pobres enfermos y ejercite la caridad cristiana" (Muriel, 1990, t. II, p. 300). Según Muriel, esta ordenanza impulsó de manera oficial el gran movimiento hospitalario de la Nueva España desde el siglo XVI y fue tomada en cuenta en el Tercer Concilio Provincial Mexicano (1585) al especificarse los lineamientos básicos. A este respecto, sólo se señalan algunos puntos:

I) Que los hospitales sean para pobres y sólo por excepción se reciba a los que tengan bienes de fortuna, pero esto solo mediante paga [...] II) Que se dé instrucción religiosa a los enfermos [...] administrando los sacramentos a los moribundos y dando a todos facilidades para oír la Santa Misa; III) Haya sala para hombres y por separado sala de mujeres (Muriel, 1990, t. II, pp. 303-304).

Éstos son los lineamientos básicos considerados para la fundación de hospitales novohispanos y fueron las medidas que se ajustaron a las Constituciones propias de cada institución o congregación que los administrara, concibiéndose desde el principio cristiano de la caridad como instituciones de carácter religioso cuya función principal no era la atención médica sino el auxilio espiritual. Eran instancias de caridad y de expiación de culpas, por lo que no eran primordialmente para enfermos, sino para todo tipo de gente pobre y desvalida.

Lo mismo ocurrió en el Hospital de San Miguel de Guadalajara desde su fundación en el siglo $\mathrm{XVI}^{8} \mathrm{y}$ hasta el siglo XVIII, incluso en las diferentes sedes que tuvo hasta la inauguración en 1794 de la Nueva Fábrica de Belén. Durante el periodo virreinal y hasta 1821, año en que se suprimen y salen de la Nueva España las diferentes congregaciones religiosas, la asistencia y administración de estos recintos estuvo en manos de distintas órdenes hospitalarias, ${ }^{9}$ que renovaron esfuerzos y ampliaron nuevas enfermerías y recintos, además de mejorar, de acuerdo con sus recursos y personal, la asistencia en ellos. Dentro del entorno de las órdenes destaca la de San Juan de Dios (juaninos), considerada la mayor de la Nueva España tanto por el número de instituciones fundadas por sus religiosos

8 Su primera sede (1581-1590) se ubicó donde actualmente es el Palacio Legislativo de la ciudad; su segunda sede (1590-1794) se estableció donde está el actual Mercado Corona, y su tercera sede (1794) corresponde al actual Hospital Civil (Oliver, 1992, p. 56).

9 tentes en la iglesia en que sus miembros hacían un voto especial: el de la hospitalidad"
(Muriel, 1990, t. II, p. 7). 
como por las que se pusieron a su cargo (Muriel, 1990, t. II, p. 8). En este mismo sentido también destacan los hipólitos, betlemitas y antonistas. De los 54 hospitales fundados en la Nueva España durante la época virreinal, 27 fueron de juaninos, 16 de hipólitos, 10 de betlemitas y 1 de los antonistas (Oliver, 1992, p. 116).

En lo que respecta a los betlemitas, en 1820 administraban 22 recintos en el Perú y 10 en la Nueva España (Oliver, 1992, p. 112), entre ellos el de Guadalajara, donde llegaron en 1704 y lo tuvieron a su cargo hasta 1802 (Oliver, 1992, pp. 133-143). El gobierno del hospital se rigió bajo las Constituciones de la Orden de Belén, aprobadas en 1687. El ejercicio de las virtudes espirituales era de suma importancia en los hospitales, como establece el artículo primero de sus constituciones:

El fin de la compañía es ocuparse muy diligentemente en el ejercicio de las obras de caridad y misericordia, así espirituales como corporales, para con todo género de personas, principalmente para los enfermos convalecientes, procurando grandemente la salud de las almas (Oliver, 1992, p. 147).

A partir de que los betlemitas se hicieron cargo de la administración del recinto en 1704, la asistencia a los enfermos retomó un carácter humanitario y caritativo. Así lo establecían sus constituciones, que privilegiaban el trato espiritual y caritativo a los convalecientes, para todo tipo de gente y con cualquier padecimiento:

No deben ser excluidos de nuestros hospitales algún género de personas, los brazos de caridad deben extenderse a todos, deben abrazar a todos [...] Así, en sus hospitales recibieron convalecientes, peregrinos, pobres, gálicos, lazarinos, enfermos de cirugía, apestados, contagiosos o epidemiados, cancerosos, rabiosos, e inclusive locos (Oliver, 1992b, p. 25).

Tal y como lo especificó el Concilio Provincial, las Constituciones de los Betlemitas se adecuaron a sus ordenanzas, y la caridad fue el elemento rector en la asistencia hospitalaria.

\section{Las salas de enfermos del Nuevo Hospital}

Según algunas descripciones, el nuevo recinto construido en 1794 incluyó iglesia, camposanto, siete salas, dos manicomios (uno para hombres y otro para mujeres), dos enfermerías (de religiosos y de pobres), dos 
escuelas (de escribir y de leer), cocina, panadería, librería, habitaciones para empleados, ropería, sala de autopsias, baño, botica y hospicio. El hospital tenía 775 camas y una capacidad para atender en un mismo momento a dos mil enfermos. ${ }^{10}$

Lo que en los registros de entradas y salidas del hospital es reflexionar y analizar, en un primer momento, sobre las estadísticas, variaciones y dinámicas generales que se presentan de forma anual y mensual entre los que ingresan, los que salen y los que mueren (ver cuadro 1 y gráfica 1).

\section{Cuadro 1}

Registros anuales de enfermos del Hospital Real de San Miguel:

ingresos, salidas y muertes (1797-1799)

\begin{tabular}{|lrrrr|}
\cline { 5 - 5 } \multicolumn{1}{r}{ Año } & 1797 & 1798 & 1799 & Total \\
\hline Ingresos & 2975 & 3205 & 2969 & 9149 \\
Salidas & 2443 & 2902 & 2689 & 8034 \\
Muertes & 347 & 401 & 236 & 984 \\
\hline
\end{tabular}

Fuente: AHJ, Libros de entradas y salidas, No. 21, 22, 23 y 24 (1797-1799).

\section{Gráfica 1}

Registros mensuales de enfermos del Hospital Real de San Miguel:

ingresos, salidas y muertes (1797-1799)

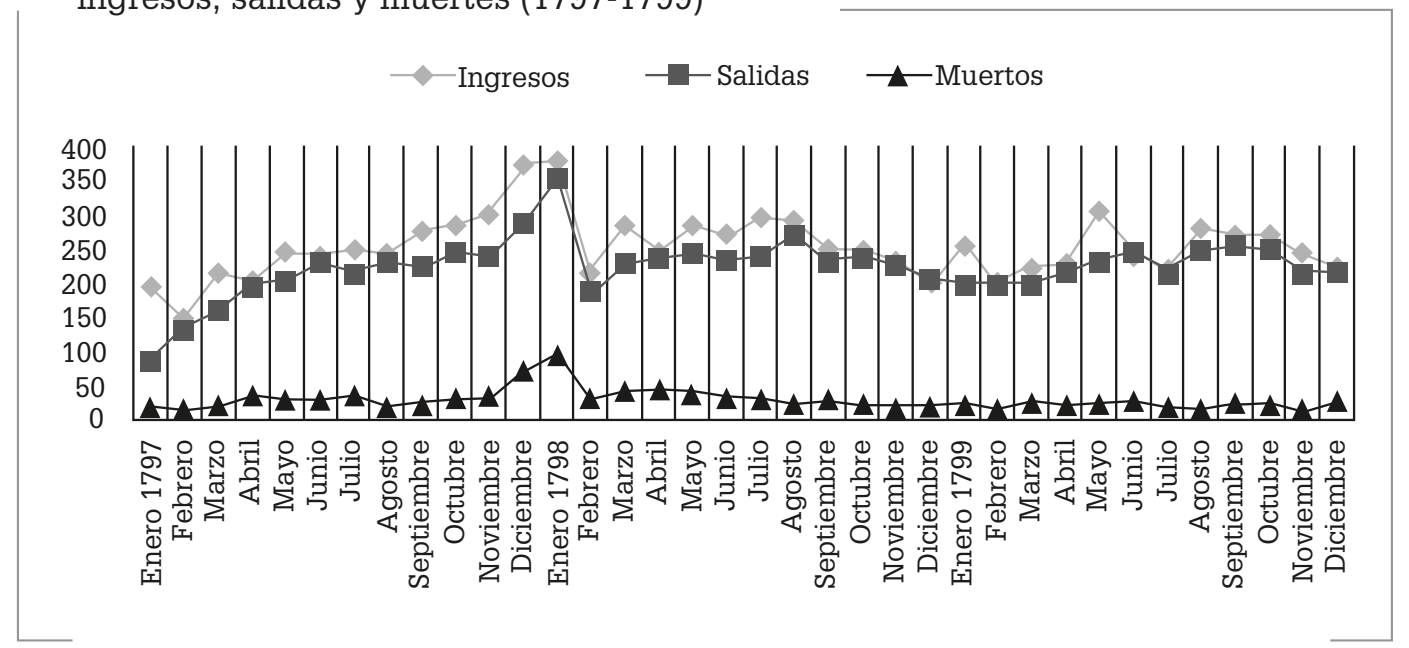

Fuente: AHJ, Libros de entradas y salidas, núm. 21, 22, 23 y 24 (1797-1799).

10 AHAG, Sección Gobierno, Serie Obras Asistenciales, El Hospital de Belén, caja 3, exp. 5 progresivo 49. 35 fojas. Inventario del Hospital Real de San Miguel de Belén, 1793-1794; y Pérez, 1988, pp. 386-395; Brun, 1982, pp. 202-203; Navarro, 1982, pp. 211-212. 
Los enfermos que ingresaban a fines de cada uno de estos años por lo común no salían hasta enero o febrero del siguiente. Por esa razón, las sumatorias entre las salidas y muertes de cada uno de estos años puede no corresponder con los totales de ingresos que se registraron durante ese mismo. Para nuestro caso, entre 1797-1799 el hospital registró un total de 9149 entradas. De todos los ingresos, durante este mismo periodo causaron salida 8034 enfermos y otros 984 murieron ahí, es decir, un total 9018 registros sólo de salidas y muertes, mientras que otros 131 ingresados a finales de 1799 salieron durante enero y febrero de 1800. Así se desglosan los 9149 registros de ingresos, salidas y muertes.

De acuerdo con el conteo anual general y capturas nominales particulares consignados durante los tres años que se presentan en el cuadro $1,{ }^{11}$ es necesario mencionar que el porcentaje en los ingresos anuales incluye a quienes registraron más de una entrada al hospital durante cada uno de los años: "dichos totales no significan el número de personas que fueron hospitalizadas, sino el número de ingresos; es decir, cuando un mismo enfermo tenía varios ingresos al hospital durante ese mismo año, era contabilizado varias veces" (Oliver, 1992, p. 307). No se puede establecer el porcentaje exacto de los reingresos que tienen estos convalecientes, aunque se detectaron algunos enfermos que estuvieron internados en el hospital al menos en cada uno de los tres años del periodo de estudio. Por lo tanto, los 9149 registros que se consignan representan el número de entradas de los tres años, aun cuando una misma persona registre varios ingresos. Independientemente de este aspecto, los datos permiten dar un acercamiento al tema.

En cuanto al lugar de origen de los enfermos ingresados al hospital y tomando en conjunto los datos, aproximadamente el $65 \%$ no se registraron como originarios de Guadalajara. ${ }^{12}$ Los datos también permiten hacer referencia a la estancia de los internados en el hospital, es decir, una serie de estimaciones generales sobre los ingresos tanto de los que salieron

11 El número de registros que se apuntan en el cuadro 1 son los que localizamos en los libros del hospital. Es necesario mencionar que los estimados en poco varían con los que presenta Oliver (1992, p. 203). La razón es que, en nuestro caso, se detectaron fojas faltantes y mutiladas en los libros.

En el origen de los registros sistematizados se detectaron un sinnúmero de localidades que fueron anotadas como lugares de origen de los enfermos, que sumaron más de 200 sitios donde hay ciudades, pueblos, villas, rancherías, etc., de diversas regiones de la Nueva España. Aquí solamente se muestra el porcentaje de los que se registraron en el hospital como originarios de Guadalajara, lo cual representa cerca del $35 \%$ de todos los datos. 
como los que murieron ahí. De las entradas consignadas durante los tres años, por lo regular registraron salida del recinto un estimado del $89.24 \%$, con un periodo de internamiento aproximado de 15 días por persona, mientras que murió el $10.75 \%$, con un periodo de 17 días por persona. ${ }^{13}$

En lo que respecta a las variaciones mensuales de los tres años señalados en la gráfica 1, tenemos lo siguiente: 1) una correspondencia entre los registros de entrada, los de salida y los de muerte, es decir, las variaciones en las series por lo regular son paralelas en los tres ejes: las altas y bajas de salidas y muertes de enfermos son proporcionales a la demanda y el impacto de sus ingresos; y 2) entre las variaciones que mes a mes presentan los ingresos, se constata un aumento entre noviembre de 1797 y enero de 1798 que hace referencia a los enfermos de viruela. Pero, ¿cómo fue la distribución de los enfermos en las salas del hospital?, ¿cuál era la concepción de estas enfermerías?, ¿cuál fue el impacto de los enfermos de viruela en el edificio y cuál la función del personal que las administraba?

La población que ingresaba se distribuía entre las salas del hospital. Se hacía una distinción de acuerdo a lo establecido en las Constituciones de la Orden de Belén aprobadas en 1687, entre espacios destinados para hombres y para mujeres, para españoles y resto de calidades, ${ }^{14}$ enfocadas en determinado padecimiento, donde eran atendidos por los religiosos betlemitas y el resto del personal del hospital. Sin embargo, hubo variaciones entre lo que estableció la regla de los betlemitas y lo que se aplicó. En ocasiones se ajustaban a las necesidades locales que presentaban las instalaciones, las ciudades y sus poblaciones (Oliver, 1992, p. 71).

$\mathrm{Al}$ ser el aspecto espiritual y religioso los ejes más importantes del hospital, tal y como se especificaba en las Constituciones de la Orden, la práctica y el saber médico se relegaban a segundo punto. Así se establece en las ordenanzas de los betlemitas que analiza Lilia Oliver (1992, pp.

13

Los periodos de internamiento se obtuvieron a partir del número de "dietas" que incluye cada registro, es decir, una dieta suministrada por día a cada enfermo como interno del hospital. Los datos se desglosan de la siguiente manera y son aproximados. Para 1797, del enfermo que registra salida suma 15 días y del que muere 15 días por persona; para 1798, del enfermo que registra salida suma 14 días y del que muere 17 días por persona; para 1799, del enfermo que registra salida suma 16 días y del que muere 20 días por persona. Vemos que la estimación del que muere en el hospital registra un aumento en días como internado.

14 "Esta separación, que se mantuvo a lo largo del siglo XVIII, respondía a que el capítulo VII de sus constituciones así lo ordenaba: estarán diversas enfermerías, separadas de los españoles, para los indios, moros y otras naciones". Oliver, 1992, p. 263. 
147-153). En cuanto los enfermos ingresaban al hospital, los religiosos les lavaban los pies, les daban de comer y los confesaban. Los betlemitas se levantaban muy temprano, barrían y tenían limpio el recinto: "Para los frailes el día se iniciaba a la hora quinta con una oración mental de una hora, a la sexta se abrían las puertas de las enfermerías y los frailes entraban para barrer, sacar los vasos y limpiar" (Oliver, 1992, p. 148).

Según las Constituciones, las actividades que más resaltan son las espirituales, oír misa y rezar antes de cada comida, como la función más importante ejercida por los betlemitas. Además, era deber del prefecto acompañar al médico por la mañana en la visita realizada a los pacientes. El resto de los religiosos debía hacerse cargo de los enfermos; mantenían en buen estado higiénico las instalaciones, daban de comer y atendían las necesidades espirituales con misas, cantos y rezos. Los enfermos comían a las once de la mañana y cenaban a las cuatro treinta de la tarde (Oliver, 1992, pp. 147-153).

En cuanto a las actividades cotidianas realizadas por los dos facultativos que durante este periodo ejercieron en el hospital, el doctor en medicina Mariano García de la Torre y el cirujano Juan González, fray Joaquín de la Concepción, padre enfermero mayor del hospital, ${ }^{15}$ escribe en 1794:

que el Padre Presidente (sin que falte más de algunas veces) acompaña al médico por la mañana a la visita general que hace a los enfermos y enfermas del hospital entre las seis y seis media, la media hora, pocos minutos más o menos, ocupa en ella; que un practicante, el boticario o su oficial y el mozo que llaman enfermero son las personas seculares que también le acompañan con el padre presidente; que por la tarde entre las tres y las cuatro, que vuelve el medico para ver a los enfermos que han ocurrido en la mañana; a excepción del practicante, le acompañan las mismas personas que por la mañana; que el medico pulsa a los enfermos, y dicta al practicante que es quien escribe las recetas en medio pliego de papel, o el boticario [...] que al cirujano le acompañan solamente cuatro practicantes, dos que viven dentro del hospital y dos que vienen de la calle, menos en las enfermerías de mujeres, a donde solamente entra el cirujano [...] que el cirujano no asiste más que por la mañana, regularmente el mismo tiempo que el médico, a excepcion

15 Esta información forma parte de la declaración que fray Joaquín de la Concepción, padre enfermero mayor del Hospital Real de San Miguel de Belén, hizo dentro del proceso judicial que en 1794 los funcionarios de la Real Audiencia efectuaron al personal de la institución. Guadalajara, 18 de junio de 1794. BPEJ, ARAG, Ramo Civil, Caja 201, Exp. 6, fojas 69 v-70 v; y Oliver, 1992, pp. 153-175. 
que tenga alguna o algunas operaciones que hacer, en que se dilata tres cuartos de hora, o una entera, que también quando hay alguna cosa urgente se llama, aunque sea de noche.

De acuerdo con la sistematización de los registros, las características que presentan los enfermos son: 1) para los hombres un $58.65 \%$ de entradas al hospital y para las mujeres el $41.34 \%$; y 2) distribuidos por rangos de edad (ver cuadro 2).

\section{Cuadro 2}

Edad de los registros de enfermos del Hospital Real de San Miguel

(1797-1799)

\begin{tabular}{|lrrrr|} 
& & & & \\
\cline { 4 - 5 } Edad & 1797 & 1798 & 1799 & Total \\
\hline 0 a 4 & 6 & 3 & 1 & 10 \\
5 a 9 & 31 & 45 & 31 & 107 \\
10 a 14 & 107 & 124 & 82 & 313 \\
15 a 19 & 349 & 408 & 296 & 1053 \\
20 a 24 & 480 & 572 & 520 & 1572 \\
25 a 29 & 390 & 409 & 341 & 1140 \\
30 a 34 & 457 & 485 & 559 & 1501 \\
35 a 39 & 251 & 209 & 203 & 663 \\
40 a 44 & 311 & 350 & 346 & 1007 \\
45 a 49 & 170 & 177 & 153 & 500 \\
50 a 54 & 195 & 162 & 197 & 554 \\
55 a 59 & 69 & 57 & 54 & 180 \\
60 a 64 & 71 & 104 & 104 & 279 \\
65 a 69 & 19 & 31 & 29 & 79 \\
70 y más... & 65 & 63 & 33 & 161 \\
Sin especificar & 4 & 6 & 20 & 30 \\
Total & 2975 & 3205 & 2969 & 9149 \\
\hline
\end{tabular}

Fuente: AHJ, Libros de entradas y salidas, No. 21, 22, 23 y 24 (1797-1799).

Es una población de todas las calidades y se conformó de la siguiente manera: indio $37.90 \%$; español $29.32 \%$; mestizo $19.65 \%$; mulato $8.98 \%$; coyote $2.27 \%$; morisco $0.61 \%$; negro $0.57 \%$; lobo $0.12 \%$; castizo $0.04 \%$; meco $0.04 \%$; y tresalbo $0.03 \%$.

De acuerdo con las características que presentan los grupos de edad, se destaca el gran porcentaje de la población adulta ubicada entre los 15 y los 39 años. El estimado alcanza prácticamente el 65\%: una población 
donde más de la mitad son hombres (mayoría de indios y españoles) que se encuentran en edad productiva.

Otro aspecto importante hace referencia al reducido porcentaje de los párvulos, en este caso la población infantil ubicada entre los 0 y los 14 años de edad, grupo que representa casi el $5 \%$. Este bajo porcentaje contrasta el impacto de las epidemias infantiles como la viruela y el sarampión, enfermedades con una elevada mortandad entre los infantes, como fue el caso de la presencia de la viruela en 1780 y 1797 en Guadalajara (Argumaniz, 2017, pp. 129-240). Los datos registrados del 5\% pueden revelar de alguna manera la postura de los padres y madres de familia al resistirse y no llevar tan fácilmente a los más pequeños a dejarlos en un hospital donde recibían ayuda en manos de extraños. Los niños se atendían en casa y eran curados con remedios tradicionales. Aunque también es necesario mencionar la existencia de casas de niños expósitos y diferentes albergues locales como casas de cuna, espacios destinados para resguardarlos, atenderlos, educarlos e instruirlos en algún oficio.

La población se distribuyó de forma separada por hombres y mujeres en las diferentes salas y espacios del hospital (ver plano 1 y cuadro 3).

De 28 salas o diferentes espacios que durante los tres años registran algún tipo de movimiento en el nuevo hospital (ver cuadro 4), resaltan varios aspectos: 1) separación de los enfermos por sexo, 16 salas son destinadas para hombres (Santiago y San Miguel se cuentan por separado, porque el registro así lo indicó), 10 para mujeres y en Patio de San Rafael y Cuartos se registran hombres y mujeres, pero de forma separada por cuartos y sexo; 2) no se localizó alguna sala para albergar determinada calidad, los diferentes grupos poblacionales, independientemente de su estatus y edad, se encuentran dispersos por todas las enfermerías, es decir, estas características no representaron criterio alguno para que el paciente fuera ingresado en determinado espacio, aunque el sexo sí lo representó; y 3) se localizaron salas donde se asistían determinadas enfermedades o padecimientos.

Antes de abordar la distribución de los enfermos en los diferentes espacios del hospital, es necesario señalar la concepción y función de cada uno de éstos. Oliver (1992, pp. 261-268), a través del Plano del Hospital de 1792, realizó un estudio muy detallado de las diferentes salas, lo cual permite analizar los datos. Señala "un total de 22 salas y 20 piezas, separadas por sexo" (Oliver, 1992, p. 261). Según la autora, las disposiciones que presentan las salas del recinto tienen su origen en los hospitales cruciformes $^{16}$ de la Edad Media (Oliver, 1992, p. 238), como el antecedente de la

${ }_{16}$ Los hospitales cruciformes se caracterizaron por la disposición de sus enfermerías 


\section{Plano 1}

Plano del Hospital Real de San Miguel de Belén (1792)

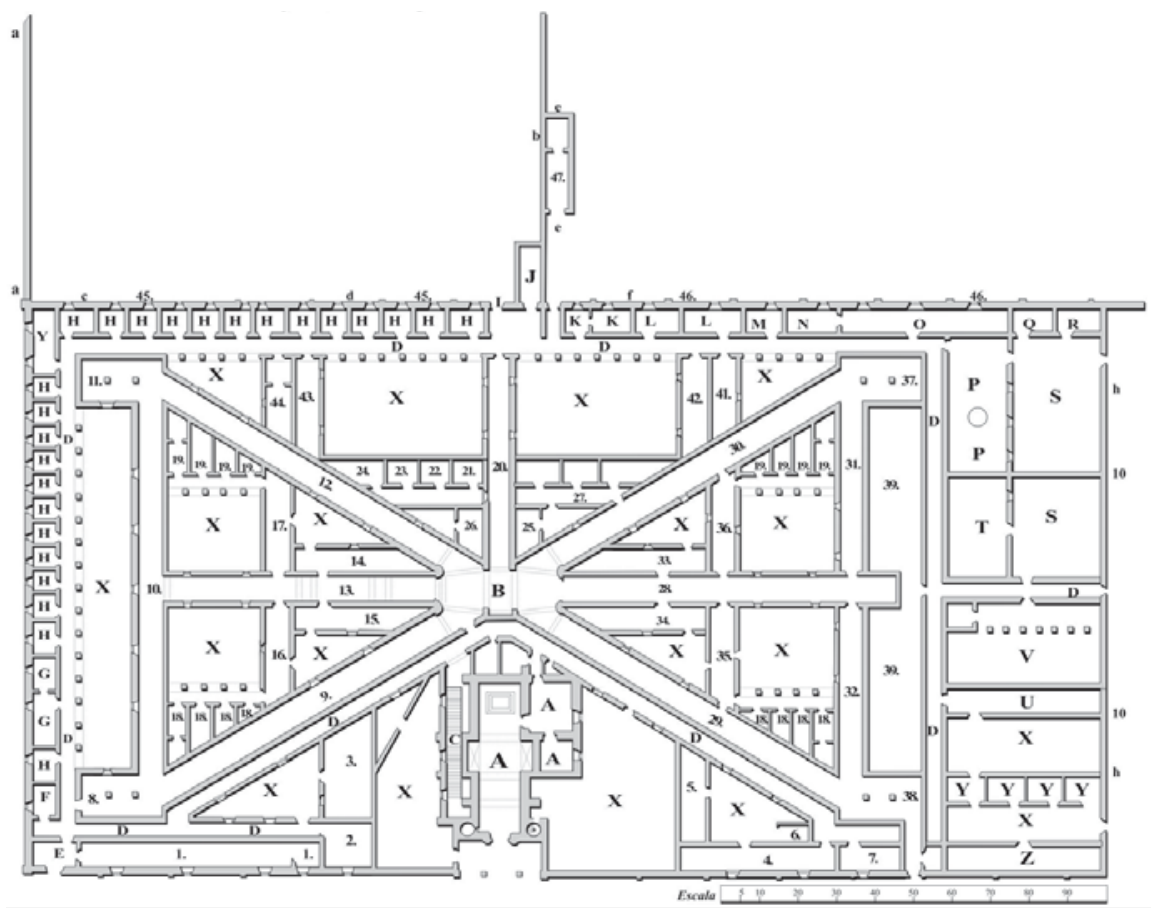

Leyenda del Plano de 1792:

"Plano de el Hospital General que el Ilustrísimo Reverendísimo Señor Don Fray Antonio Alcalde, Dignísimo Obispo de Guadalajara, capital de la Nueva Galicia, construyó a sus expensas en esta ciudad y por su Disposición se presenta a S. M. para que le dé el Destino que fuere de su Real agrado: Delineado por el Capitán de el Real Cuerpo de Ingenieros Don Narciso Codina".

Notas. $1^{1}$. La pared A continuada de 186 varas con la igual b, sobre el lado c.d. de 132 varas forma un rectángulo de 24.552 varas cuadradas, que es la huerta. $2^{\mathrm{a}}$. La pared e.e de 250 varas sobre la f.f. de 204 forma un rectángulo de 51.000 varas cuadradas, que es el campo santo. $3^{a}$. La pared g. de 56 varas, sobre la h.h. de 150 varas forma un rectángulo de 8.400 varas cuadradas, corral de ganado con puerta al campo. $4^{\mathrm{a}}$. Este hospital no tiene piso alto, pero su fábrica está bastante elevada sobre el terreno, bien construida, y cubierta con azotea, con suficientes luces, así por medio de ventanas, como linternas, y claraboyas. Tiene cañerías para dar agua a todas las oficinas necesarias, con su tarjeas de desagüe. $5^{\mathrm{a}}$. Las camas están de firme de mampostería, arrimadas a lo largo de las salas, y paralelas a sus paredes, y son 775, con las divisiones, y comodidad posible, y lugar para poner otras. $6^{\text {a }}$. Salas, piezas y oficinas, destinadas para mujeres, están con entera separación. Guadalajara 15 de septiembre de 1792 .

Fuente: AHJ, Mapoteca, Plano 7.7, 1792, 518, RF-53 y Oliver, 1992, pp. 253-254. Elaboración propia a partir del Plano de 1792. 


\section{Cuadro 3}

Salas y espacios de acuerdo al Plano de1792

\begin{tabular}{|c|c|c|c|c|c|c|c|}
\hline No. * & Sala / Espacio & No. ${ }^{*}$ & Sala / Espacio & No.* & Sala / Espacio & No. ${ }^{*}$ & Sala / Espacio \\
\hline A & $\begin{array}{l}\text { Iglesia, coro, } \\
\text { sacristía y ante- } \\
\text { sacristía }\end{array}$ & S & $\begin{array}{l}\text { Patios para } \\
\text { leña }\end{array}$ & 13 & La de Dios Hijo & 32 & $\begin{array}{l}\text { De Santa Ana, } \\
\text { cirugía }\end{array}$ \\
\hline B & $\begin{array}{l}\text { Capilla donde } \\
\text { se pone el altar } \\
\text { para que oigan } \\
\text { misa los enfer- } \\
\text { mos }\end{array}$ & $\mathrm{T}$ & Amasijo & 14 & $\begin{array}{l}\text { La de San } \\
\text { Francisco de } \\
\text { Paula }\end{array}$ & 33 & Del Refugio \\
\hline $\mathrm{C}$ & $\begin{array}{l}\text { Escalera para } \\
\text { subir al coro }\end{array}$ & V & $\begin{array}{l}\text { Pieza para } \\
\text { las lavande- } \\
\text { ras }\end{array}$ & 15 & $\begin{array}{l}\text { La de los Do- } \\
\text { lores, ambas } \\
\text { para unciones }\end{array}$ & 34 & $\begin{array}{l}\text { Del V. P. Ve- } \\
\text { tancourt }\end{array}$ \\
\hline D & Corredores & $\mathrm{U}$ & Recreo & 16 & $\begin{array}{l}\text { La de San Jeró- } \\
\text { nimo, gálicos }\end{array}$ & 35 & $\begin{array}{l}\text { De la Sangre } \\
\text { de Cristo }\end{array}$ \\
\hline $\mathrm{E}$ & Portería & $\mathrm{X}$ & Patio & 17 & $\begin{array}{l}\text { La de San Ni- } \\
\text { colás, heridos }\end{array}$ & 36 & $\begin{array}{l}\text { La de Guada- } \\
\text { lupe }\end{array}$ \\
\hline $\mathrm{F}$ & $\begin{array}{l}\text { Cuarto del por- } \\
\text { tero }\end{array}$ & $\mathrm{Y}$ & $\begin{array}{l}\text { Piezas para } \\
\text { sillas, guar- } \\
\text { niciones, } \\
\text { carnicería, } \\
\text { etc. }\end{array}$ & 18 & $\begin{array}{l}\text { Piezas para lo- } \\
\text { cos y delirio }\end{array}$ & 37 & De San Rafael \\
\hline G & $\begin{array}{l}\text { Sala de recibo } \\
\text { y cuarto para el } \\
\text { padre general }\end{array}$ & $\mathrm{Z}$ & $\begin{array}{l}\text { Caballeriza y } \\
\text { pajar }\end{array}$ & 19 & $\begin{array}{l}\text { Para rabia y } \\
\text { contagio }\end{array}$ & 38 & $\begin{array}{l}\text { De San Miguel } \\
\text { y entrada de } \\
\text { los enfermos }\end{array}$ \\
\hline $\mathrm{H}$ & $\begin{array}{l}\text { Celdas de reli- } \\
\text { giosos }\end{array}$ & 1 & $\begin{array}{l}\text { Escuela de } \\
\text { muchachos }\end{array}$ & 20 & $\begin{array}{l}\text { Sala de Nues- } \\
\text { tra Señora } \\
\text { de Betlem y } \\
\text { entrada de los } \\
\text { religiosos a las } \\
\text { enfermerías }\end{array}$ & 39 & $\begin{array}{l}\text { Corral de ga- } \\
\text { llinas }\end{array}$ \\
\hline $\mathrm{Y}$ & $\begin{array}{l}\text { Enfermería de } \\
\text { religiosos }\end{array}$ & 2 & Botica & 21 & $\begin{array}{l}\text { Cuarto del en- } \\
\text { fermero mayor }\end{array}$ & 40 & De ovejas \\
\hline I & Huerta & 3 & $\begin{array}{l}\text { Almacén de } \\
\text { Idem }\end{array}$ & 22 & Ayudante & 41 & Harinero \\
\hline $\mathrm{J}$ & Común & 4 & Pupilaje & 23 & Capellán & 42 & Procuración \\
\hline $\mathrm{K}$ & $\begin{array}{l}\text { Secretaría y } \\
\text { librería }\end{array}$ & 5 & Refectorio & 24 & Ropero & 43 & Ropería \\
\hline L & $\begin{array}{l}\text { Sala de semillas } \\
\text { y despensa }\end{array}$ & 6 & Común & 25 & $\begin{array}{l}\text { Baño para mu- } \\
\text { jeres }\end{array}$ & 44 & Sastrería \\
\hline
\end{tabular}




\begin{tabular}{|c|c|c|c|c|c|c|c|}
\hline No. ${ }^{*}$ & Sala / Espacio & No.* & Sala / Espacio & No.* & Sala / Espacio & No.* & Sala / Espacio \\
\hline $\mathrm{M}$ & $\begin{array}{l}\text { Cuarto del des- } \\
\text { pensero }\end{array}$ & 7 & $\begin{array}{l}\text { Celda del } \\
\text { Rector }\end{array}$ & 26 & Para hombres & 45 & $\begin{array}{l}\text { Puerta de la } \\
\text { huerta }\end{array}$ \\
\hline $\mathrm{N}$ & Reclusión & 8 & $\begin{array}{l}\text { Entrada a las } \\
\text { salas de en- } \\
\text { fermos y la } \\
\text { de San José }\end{array}$ & 27 & $\begin{array}{l}\text { Habitación } \\
\text { para las enfer- } \\
\text { meras }\end{array}$ & 46 & Campo santo \\
\hline $\mathrm{O}$ & Refectorio & 9 & $\begin{array}{l}\text { La de Dios } \\
\text { Padre, para } \\
\text { fiebres }\end{array}$ & 28 & $\begin{array}{l}\text { Sala del Sal- } \\
\text { vador }\end{array}$ & 47 & $\begin{array}{l}\text { Depósito de } \\
\text { cadáveres y } \\
\text { capilla }\end{array}$ \\
\hline $\mathrm{P}$ & Cocina & 10 & $\begin{array}{l}\text { La de Santia- } \\
\text { go y San Mi- } \\
\text { guel, cirugía }\end{array}$ & 29 & $\begin{array}{l}\text { Del Corazón de } \\
\text { Jesús }\end{array}$ & & \\
\hline $\mathrm{Q}$ & $\begin{array}{l}\text { Cuarto para co- } \\
\text { cineros }\end{array}$ & 11 & $\begin{array}{l}\text { La de San } \\
\text { Pedro para } \\
\text { eclesiásticos }\end{array}$ & 30 & $\begin{array}{l}\text { De la Pasión, } \\
\text { fiebres }\end{array}$ & & \\
\hline $\mathrm{R}$ & Carbonera & 12 & $\begin{array}{l}\text { La del Espíri- } \\
\text { tu Santo }\end{array}$ & 31 & $\begin{array}{l}\text { De Santa Ro- } \\
\text { salía }\end{array}$ & & \\
\hline
\end{tabular}

Fuente: AHJ, Mapoteca, Plano 7.7, 1792, 518, RF-53. * Número o letra con el que se localizan en el plano de 1792.

\section{Cuadro 4}

Salas y número de registros de enfermos

del Hospital Real de San Miguel (1797-1799)

\begin{tabular}{|c|c|c|c|c|c|c|c|c|}
\hline \multicolumn{6}{|c|}{ Salas para hombres } & \multicolumn{3}{|c|}{ Salas para mujeres } \\
\hline No.* & $\begin{array}{c}\text { Sala/ } \\
\text { Espacio }\end{array}$ & Cantidad & No. * & $\begin{array}{c}\text { Sala/ } \\
\text { Espacio }\end{array}$ & Cantidad & No. ${ }^{*}$ & $\begin{array}{c}\text { Sala/ } \\
\text { Espacio }\end{array}$ & Cantidad \\
\hline $\mathrm{H}$ & Celda & 3 & 18 & $\begin{array}{l}\text { Cuarto del } \\
\text { Chocolatero }\end{array}$ & 3 & 18 & Cuartos & 12 \\
\hline 8 & San José & 1 & 18 & Cuartos & 2 & 18 & San Blas & 1 \\
\hline 9 & $\begin{array}{l}\text { Dios } \\
\text { Padre }\end{array}$ & 164 & 37 & $\begin{array}{l}\text { Patio de los } \\
\text { locos }\end{array}$ & 1 & 18 & $\begin{array}{l}\text { Patio de San } \\
\text { Gabriel }\end{array}$ & 7 \\
\hline 10 & $\begin{array}{l}\text { San } \\
\text { Miguel }\end{array}$ & 245 & 37 & San Rafael & 1 & 18 & $\begin{array}{l}\text { Patio de San } \\
\text { Blas }\end{array}$ & 7 \\
\hline 10 & Santiago & 30 & 37 & $\begin{array}{l}\text { Patio de } \\
\text { San Rafael }\end{array}$ & 28 & 28 & El Salvador & 2,656 \\
\hline 11 & San Pedro & 22 & $* *$ & $\begin{array}{l}\text { San } \\
\text { Antonio }\end{array}$ & 2 & 29 & $\begin{array}{l}\text { Corazón de } \\
\text { Jesús }\end{array}$ & 849 \\
\hline
\end{tabular}




\begin{tabular}{|c|c|c|c|c|c|c|c|c|}
\hline \multicolumn{6}{|c|}{ Salas para hombres } & \multicolumn{3}{|c|}{ Salas para mujeres } \\
\hline No. ${ }^{*}$ & $\begin{array}{c}\text { Sala/ } \\
\text { Espacio }\end{array}$ & Cantidad & No. ${ }^{*}$ & $\begin{array}{c}\text { Sala/ } \\
\text { Espacio }\end{array}$ & Cantidad & No. ${ }^{*}$ & $\begin{array}{c}\text { Sala/ } \\
\text { Espacio }\end{array}$ & Cantidad \\
\hline 12 & $\begin{array}{l}\text { Espíritu } \\
\text { Santo }\end{array}$ & 1,770 & ** & $\begin{array}{l}\text { Patio de } \\
\text { San } \\
\text { Antonio }\end{array}$ & 3 & 30 & La Pasión & 133 \\
\hline 13 & Dios Hijo & 2,895 & & $\begin{array}{l}\text { Sin } \\
\text { especificar }\end{array}$ & 3 & 33 & El Refugio & 82 \\
\hline 14 & $\begin{array}{l}\text { San } \\
\text { Francisco } \\
\text { de Paula }\end{array}$ & 71 & & & & 34 & $\begin{array}{l}\text { V. P. } \\
\text { Vetancourt }\end{array}$ & 19 \\
\hline 15 & $\begin{array}{l}\text { Los } \\
\text { Dolores }\end{array}$ & 118 & & & & 35 & $\begin{array}{l}\text { La Sangre } \\
\text { de Cristo }\end{array}$ & 10 \\
\hline 16 & $\begin{array}{l}\text { San } \\
\text { Jerónimo }\end{array}$ & 1 & & & & 37 & $\begin{array}{l}\text { Patio de San } \\
\text { Rafael }\end{array}$ & 1 \\
\hline 17 & $\begin{array}{l}\text { San } \\
\text { Nicolás }\end{array}$ & 3 & & & & & $\begin{array}{l}\text { Sin } \\
\text { especificar }\end{array}$ & 6 \\
\hline Total & hombres & & & & 5,366 & Total & mujeres & 3,783 \\
\hline
\end{tabular}

* Número o letra con el que se localizan en el plano de 1792.

** No se localizó en el plano de 1792.

Fuente: AHJ, Libros de entradas y salidas, No. 21, 22, 23 у 24 (1797-1799).

planta radiada y como el tipo de arquitectura ${ }^{17}$ que a finales del siglo XVIII matizó el carácter religioso del hospital, además de traslucir el ejercicio espiritual que caracterizó a los betlemitas en la asistencia de enfermos.

Sobre la disposición que guarda el repartidor, éste representa "el lugar donde convergen las siete salas que son radiadas: se trata del crucero, también llamado repartidor, indicado en el plano de 1792 con una B, en el

en dos largas crujías, las cuales formaban una cruz griega, en medio de las cuales se colocaba un altar para celebrar los oficios divinos. Oliver, 1992, p. 238.

El panóptico, como otro tipo de arquitectura de fines del siglo XVIII que presenta similitudes con respecto a la organización de las plantas radiadas hospitalarias, fue llevado a la práctica por Jeremías Bentham en 1787: "principio constructivo que le pareció aplicable a cualquier tipo de establecimiento en el que personas de cualquier condición hubieran de ser mantenidas bajo vigilancia", Bentham, 1980, p. 7. A decir de Michel Foucault, es un sistema arquitectónico y óptico cuyo procedimiento disciplinario es aplicable a diferentes instituciones: "también, hace obra de naturalista. Permite establecer las diferencias: en los enfermos, observar los síntomas de cada cual, sin que la proximidad de las camas, la circulación de los miasmas, los efectos del contagio mezclen los cuadro clínicos". Foucault, 1984, p. 207. 
cual se encontraba la capilla donde se pone el altar para que oigan misa los enfermos" (Oliver, 1992, p. 260). Con respecto a las enfermerías tanto de hombres como de mujeres, "está muy claro que la distribución dada a las salas tuvo como eje principal las enfermedades epidémicas" (Oliver, 1992, p. 262). En este sentido, tal y como se señala en la explicación del plano 1 (cuadro 3) y en el análisis de Oliver, las destinadas para fiebres de hombres fueron Espíritu Santo, Dios Hijo y Dios Padre, y para mujeres, La Pasión y Corazón de Jesús; San José, para españoles; Santiago y San Miguel se destinaron para enfermos de cirugía; San Nicolás se destinó para heridos; en San Francisco de Paula y Los Dolores se atendieron las "unciones"; San Pedro para eclesiásticos; piezas destinadas para "locos y delirio" y "rabia y contagio", para hombres y mujeres con estos males; y la Sala de Venerable Vetancourt para parturientas (Oliver, 1992, pp. 261-268).

De acuerdo con la sistematización de los registros hospitalarios, se presenta una mayor presencia de enfermos sólo en cuatro espacios que, según el Plano, son de las salas más grandes: dos de hombres y dos de mujeres.

\section{Cuadro 5}

Salas del Hospital Real de San Miguel con mayor número de registros de enfermos y muertos (1797-1799)

\begin{tabular}{|llcc|}
\multicolumn{1}{|c}{ No. ${ }^{*}$} & Salas & Registros de enfermos & Registros de muertos \\
\cline { 2 - 4 } & & $(\%)$ & $(\%)$ \\
\hline 13 & Dios Hijo & 31.64 & 39.73 \\
28 & Espíritu Santo & 19.34 & 4.77 \\
29 & El Salvador & 29.03 & 34.34 \\
Total & Corazón de Jesús & 9.27 & 3.55 \\
* Número con el que se localizan en el plano de 1792. & 82.39 \\
Fuente: AHJ, Libros de entradas y salidas, No. 21, 22, 23 y 24 (1797-1799).
\end{tabular}

De 28 salas registradas, cuatro representan básicamente el $90 \%$ de los pacientes del hospital y son las mismas donde se presentó el mayor porcentaje de muertes. En el caso de los hombres, la que generó mayor demanda es Dios Hijo, con el $31 \%$ de todos ingresos al hospital de todos los grupos poblacionales masculinos (indio, español, mulato, etc.) y rangos de edad. Ese espacio también registró el mayor índice de mortandad masculina, con el 40\%. Para los mismos hombres, también se destaca el estimado que representó Espíritu Santo, con un 19\% del total de todas las calidades y con una mortandad del $5 \%$. 
En lo que respecta a los espacios de mujeres, El Salvador registró casi el 30\% de las enfermas y un 35\% de índice de mortandad; en Corazón de Jesús el dato constata un $10 \%$ de las enfermas y un $4 \%$ de mortandad. En estos espacios la situación debió ser crítica para las enfermeras que atendieron las salas. Si bien es cierto que los religiosos, de acuerdo con lo prescrito por sus Constituciones, no trataban directamente a las pacientes, lo debieron haber hecho a través de tres enfermeras que, al menos desde 1794, posiblemente seguían laborando en el recinto: Rafaela Belaustiquin, Margarita Mercado y Paula Carrillo (Oliver, 1992, p. 262). Aunque no se descarta que ante la emergencia de tal número de enfermas seguramente también fueron asistidas por el resto de los trabajadores, mozos y demás religiosos del recinto, independientemente de que las Constituciones lo prohibieran. Esto se deduce porque estas dos salas durante los tres años del estudio alcanzaron un estimado de 3500 registros, es decir el 38\% de los ingresos. Las atenciones seguramente se cubrieron por un grupo más amplio, que posiblemente incluía hombres, y no sólo por las tres mujeres que trabajaban en el hospital, ya que las circunstancias lo requerían y justificaban, ${ }^{18}$ más aún con la presencia de una epidemia como la de viruela.

La viruela, una de las enfermedades más mortíferas que ha enfrentado el ser humano y uno de los padecimientos más frecuentes y devastadores de la época colonial, ${ }^{19}$ "afectó a los recién nacidos y aumentó la mortalidad infantil. Los adultos atacados fueron algo menos, salvo en condiciones de contacto próximo, familiar, en los pueblos, o de aglomeración, o en los cuarteles y aun en los hospitales" (Bustamante, 1982, p. 74). Las formas en que el virus se propagó fueron a través del aire, por el contacto entre los humanos o de piel a piel, por descargas respiratorias entre una persona enferma y una sana, y por objetos contaminados. ${ }^{20} \mathrm{La}$

18 "Los frailes únicamente tenían acceso a las salas de los hombres, ya que se les prohibía entrar a las de mujeres [...] aunque tampoco las mujeres podían ingresar a las salas de los hombres". Sin embargo, a pesar de esta situación, Oliver agrega que, de acuerdo con las necesidades que presentaron los hospitales, en ocasiones los principios debieron modificarse. Oliver, 1992, pp. 261 y 271. Lilia Oliver (2008, p. 81) señala la presencia de la viruela durante estos años: 1521, $1615-1616,1653,1663,1678,1687,1701,1711,1748,1761-1762$, 1779-1780, 1793 y 17971798. A dicha periodicidad, agrega para el caso de Guadalajara una más en 1815. "La facilidad de trasmisión del virus en las gotitas de saliva y las secreciones de las vías respiratorias y el material de las lesiones de la piel explica la dispersión a imperios, repúblicas y poblaciones por los infectados que huían y llegaban a otros pueblos durante el periodo de incubación, de doce días en promedio, y la inmensa e inmediata morbilidad e incalculable mortalidad" (Bustamante, 1982, p.72). 
trasmisión desde luego era desconocida en este contexto, y por supuesto por el personal del Hospital de Belén.

Una epidemia representaba para las poblaciones novohispanas un periodo de crisis social y de mortandad. En lo que respecta a esta epidemia de viruela que se presentó en Guadalajara, se señalan sólo algunos lineamientos del impacto que tuvo en la ciudad y algunas acciones que en el contexto se emprendieron para reducir los estragos.

Según lo que han demostrado los trabajos más actuales que han abordado el impacto de la enfermedad en la ciudad (Argumaniz, 2017, pp. 129240), se establece que en Guadalajara, durante la segunda mitad del siglo XVIII, su presencia se registró en tres ocasiones (1762, 1780 y 1797-1798), con un rango aproximado de 18 años entre cada epidemia, circunstancias que son explicadas por las características y facilidad de su trasmisión. Además de la viruela, también hubo brotes de otros padecimientos que igualmente generaron sobremortalidad, como "los años del hambre" de 1785-1786, una de las crisis demográficas más cruentas y con mayor impacto del siglo XVIII en la Nueva España (Oliver, 1992b, p. 7). Como se observa, fue un contexto que se caracterizó por la presencia de este tipo de lapsos catastróficos que se presentaron no sólo en Guadalajara sino en todo el territorio novohispano, causando gran número de defunciones.

Este grave impacto de las epidemias a finales del siglo XVIII dio pie a la puesta en marcha de iniciativas sociales en beneficio de la población. Desde la perspectiva institucional, las autoridades civiles y religiosas adoptaron medidas para enfrentar los daños. Para el caso de la capital virreinal se establecieron ciertas acciones:

En cuanto a medidas puramente sanitarias, las órdenes dadas por las juntas fueron de lo más acertadas. Nombraron médicos de oficio encargados de visitar y asistir a los enfermos [...] Prohibieron los velorios, ordenaron sepultar los cadáveres inmediatamente que se había comprobado la defunción y cubrirlos con una capa gruesa de cal viva, destruir las ropas y enseres que hubieran estado en contacto con los enfermos, asear las habitaciones de los enfermos limpiando [...] y finalmente encender grandes hogueras [...] para purificar el aire por donde se suponía se producía el contagio (Somolinos, 1982, p. 243).

A decir de Sherburne Cook (1982, p. 306), prácticas como la inoculación ${ }^{21}$ representaron una de las medidas que, pese a la incertidumbre que

21 La práctica o técnica consistía "en trasplantar pus de las pústulas de un enfermo de viruela a una incisión o punción en la piel de una persona sana" con la finalidad de 
en un principio causó su aplicación, fue efectiva para reducir los efectos de estas epidemias. El autor señala lo siguiente:

Para la historia de la inmunología de la viruela, la epidemia de 1797 es interesante porque proporciona información apreciable no de la vacunación, sino del procedimiento más primitivo de la inoculación que se empleaba antes del descubrimiento de Jenner. Este método, que consistía esencialmente en transferir el virus de la viruela de un ser humano a otro, se usó durante casi todo el siglo XVIII. No obstante los esfuerzos oficiales para introducirlo en América Latina, no se había empleado mucho antes de la epidemia de 1779, cuando demostró su utilidad. Por consiguiente, se generalizó su empleo en 1797 (Cook, 1982, p. 306).

A causa del impacto de estas epidemias en la población, que se reflejó en los recurrentes periodos de sobremortalidad con la que se presentaron durante la época virreinal, se propusieron medidas como la inoculación, que tuvieron mayor efecto a fines del siglo XVIII, cuando poco a poco fueron aceptadas por la población. Aun así, esta práctica y la vacuna contra la viruela que se introdujo a través de la Real y Filantrópica Expedición de Balmis en 1804 representaron las soluciones más eficaces del momento.

Con respecto al impacto que muestran los enfermos de viruela en el Hospital de Belén (ver gráfica 1), se constata un alza en los ingresos al hospital a finales de 1797 y principios de 1798, al momento de registrarse la epidemia en la ciudad (Argumaniz, 2017, pp. 129-240). De acuerdo con el aumento general, independientemente de que se trate de virulentos o no, se muestra que en septiembre de 1797 inicia el ascenso del número de enfermos en el hospital y en enero de 1798 alcanza el punto más elevado de entradas de los tres años; a partir de este mes, poco a poco descendió el número de registros y en agosto se muestra un descenso considerable.

Durante estos años los registros hospitalarios consignan el nombre de la enfermedad y la causa de muerte, y se hace referencia de manera explícita a los enfermos y muertos de viruela. Entre octubre de 1797 y abril de 1798 la captura nominal alcanzó un total de 327 virulentos: 194 hombres y 133 mujeres. De estos 327 enfermos, en 214 registros se indica que salieron del hospital, mientras que en 113 se señala que murieron allí mismo. ${ }^{22}$ De

producir y crear "viruelas benignas", y así provocar inmunidad contra la enfermedad, aunque en ocasiones se ocasionaba la muerte de la persona. Cooper, 1980, p. 85.

22

Éstas son las cantidades que se contabilizaron en nuestras capturas nominales. Sin embargo, dentro de los resúmenes de los libros se indica que los ingresos de virolentos 
acuerdo con el dato, éstas son las variaciones que presentó el hospital entre los ingresos, salidas y muertos, sólo por viruela.

\section{Gráfica 2}

Registros de los virulentos en el Hospital Real de San Miguel:

ingresos, salidas y muertos (1797-1798)

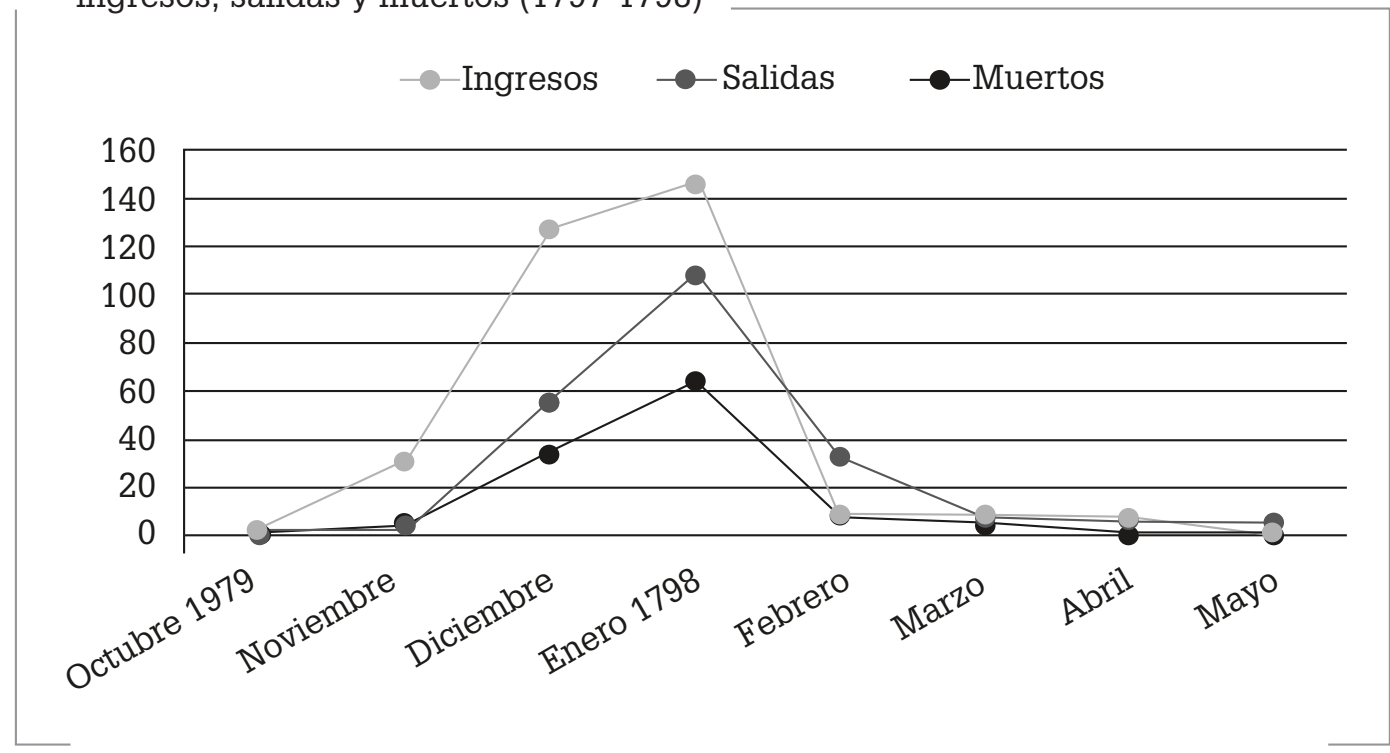

Fuente: AHJ, Libros de entradas y salidas, No. 21, 22 y 23 (1797-1798). Elaboración propia

En lo que respecta a los virulentos que salieron y murieron, a los primeros corresponden 214 registros (65.44\%), y a los segundos 113 (34.55\%). Este dato también permite construir un promedio o estimación de acuerdo a los días que fueron asistidos y salieron, o los que también fueron asistidos pero murieron. De los que salieron, la estimación alcanzó un aproximado de 19 días por virulento recluido en el hospital. En cambio, con los que murieron del mismo padecimiento la estimación alcanzó 11 días por persona. ${ }^{23}$

De acuerdo con las características generales que presentan los enfermos de viruela, se señala lo siguiente: rango de edad y calidad de los que ingresan, salen y mueren.

23 corresponde al deterioro que presenta la fuente.

Las estimaciones que se presentan se hicieron a través del dato "dietas", que corresponde al mismo número de días que cada enfermo estuvo internado en el hospital. 


\section{Gráfica 3}

Periodos de edad de los enfermos por viruela del Hospital Real de San Miguel: ingresos, salidas y muertos (1797-1798)

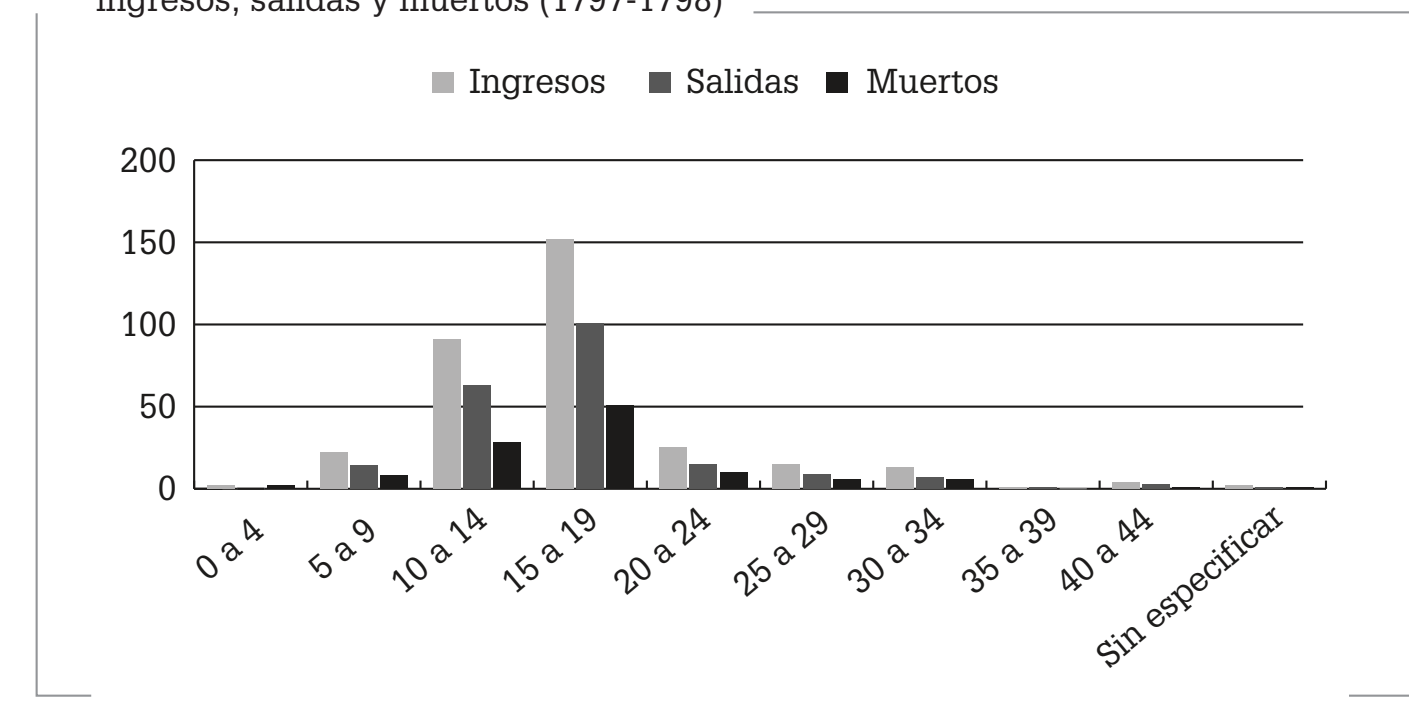

Fuente: AHJ, Libros de entradas y salidas, núm. 21, 22 y 23 (1797-1798). Elaboración propia

\section{Gráfica 4}

Calidad de los enfermos por viruela del Hospital Real de San Miguel: ingresos, salidas y muertos (1797-1798)

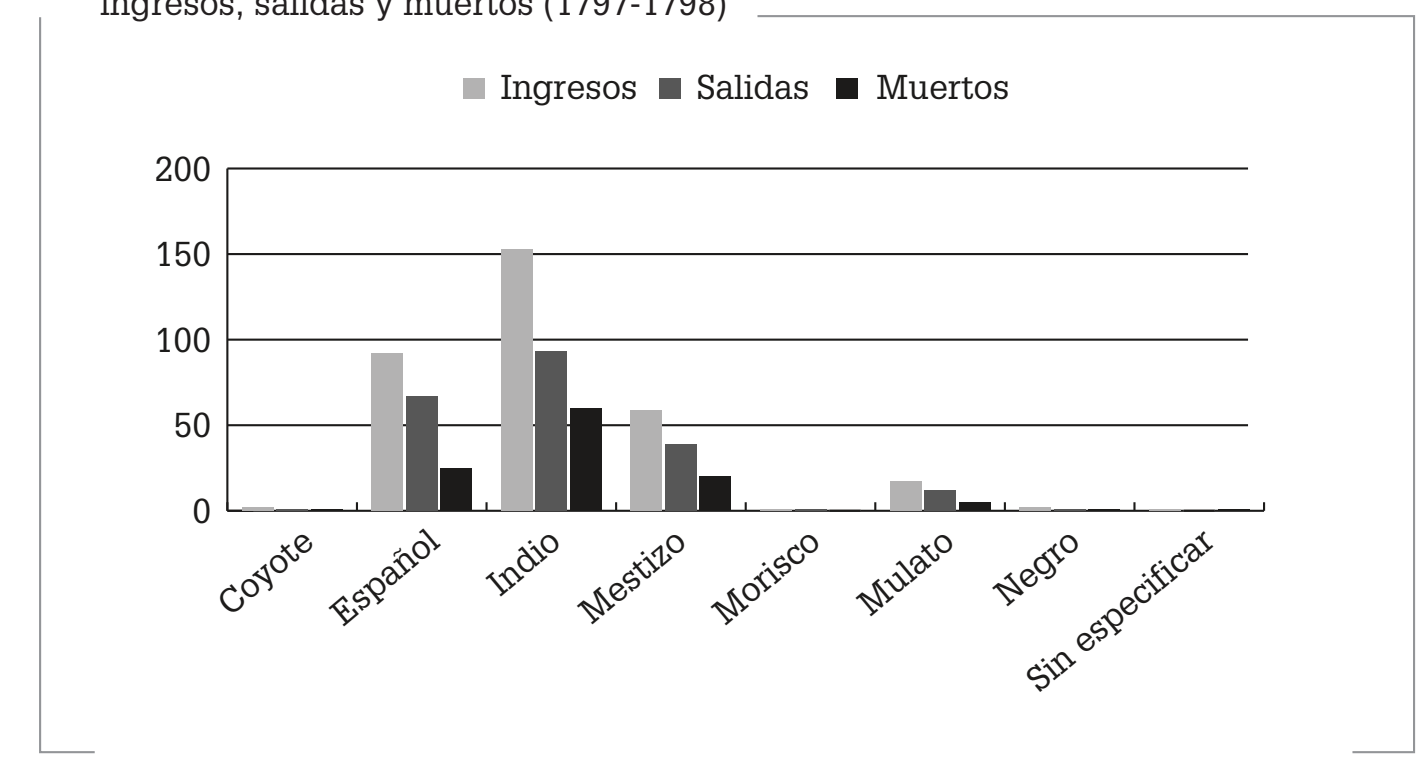

Fuente: AHJ, Libros de entradas y salidas, núm. 21, 22 y 23 (1797-1798). Elaboración propia

Recordemos que lo que interesa destacar con los registros de viruela es el impacto y las características de los enfermos en el hospital. De acuerdo con los datos, los enfermos de viruela que ingresaron se con- 
centran por lo común en tres calidades: indio, español y mestizo, y en dos grupos de edad: de 0 a 14 años, 115 casos, de éstos salieron 77 y murieron 38 párvulos, es decir, bajo esta categoría de edad falleció sólo el $11.62 \%$ de todos los ingresados como enfermos de viruela, mientras que para los adultos de 15 a 44 años, ingresaron al recinto un total de 210 enfermos, salieron 136 y murieron 74 personas, es decir, en este rango de edad murió el $22.62 \%$ de todos los ingresados. ${ }^{24}$

Como podemos observar, se registraron más defunciones de viruela en adultos (65.48\%) que en los párvulos (33.62\%). Este dato debe ser tomado con cautela. Según han demostrado los estudios de historia demográfica sobre el tipo de población que afectó la viruela en la Nueva España, tuvo mayor impacto en la población infantil menor de 14 años; sin embargo, este dato puede ser visto desde diferentes ejes: en primer término, hay que señalar que posiblemente se trate de un subregistro, es decir, una confusión por parte del religioso betlemita al momento de anotar en el libro de entradas la presencia de viruela en adultos. Partimos del hecho de que tal enfermedad se desarrollaba en diferentes fases, provocaba síntomas y el personal del recinto a veces no los detectaba por estar el virus en periodo de incubación, aunque era muy evidente cuando la enfermedad estaba desarrollada: se presentaban pústulas, granos, cicatrices y deformidades, principalmente en el rostro.

Independientemente de esta situación, para el caso de virulentos adultos posiblemente se trate de individuos que no estaban inmunizados, es decir, personas que no habían estado en contacto con brotes anteriores; para el caso de los párvulos, el bajo porcentaje de los que ingresaron al hospital, es decir, tan solo 115 niños (de los que murieron 38) de una enfermedad que se presentaba por lo regular en la población infantil, representa una pequeña muestra del gran impacto que debió tener la epidemia en la ciudad. No es objetivo del presente trabajo hacer un comparativo con los niños que murieron por esta misma enfermedad en los diferentes curatos de Guadalajara para arrojar datos más precisos, aunque sí se puede mencionar, según lo demostrado por Argumaniz (2017, pp. 129-240) en su estudio sobre la epidemia de viruela en Guadalajara durante 1797-1798, que la causa de muerte no es asentada de manera específica en todas las parroquias, de ahí que solo pueda mencionarse la mortalidad general de la ciudad para estos dos años con un registro de edades se omiten, por eso no se incluyen en dichos porcentajes. En su gráfica se apuntan en "sin especificar". 
1483 muertes, estimado que incluye un mayor impacto en la población infantil (Argumaniz, 2017, pp. 129-240).

Otro dato que interesa destacar es el espacio donde fueron confinados los enfermos de viruela (ver Gráfica 5).

\section{Gráfica 5}

Salas de enfermos por viruela del Hospital Real de San Miguel (1797-1798)

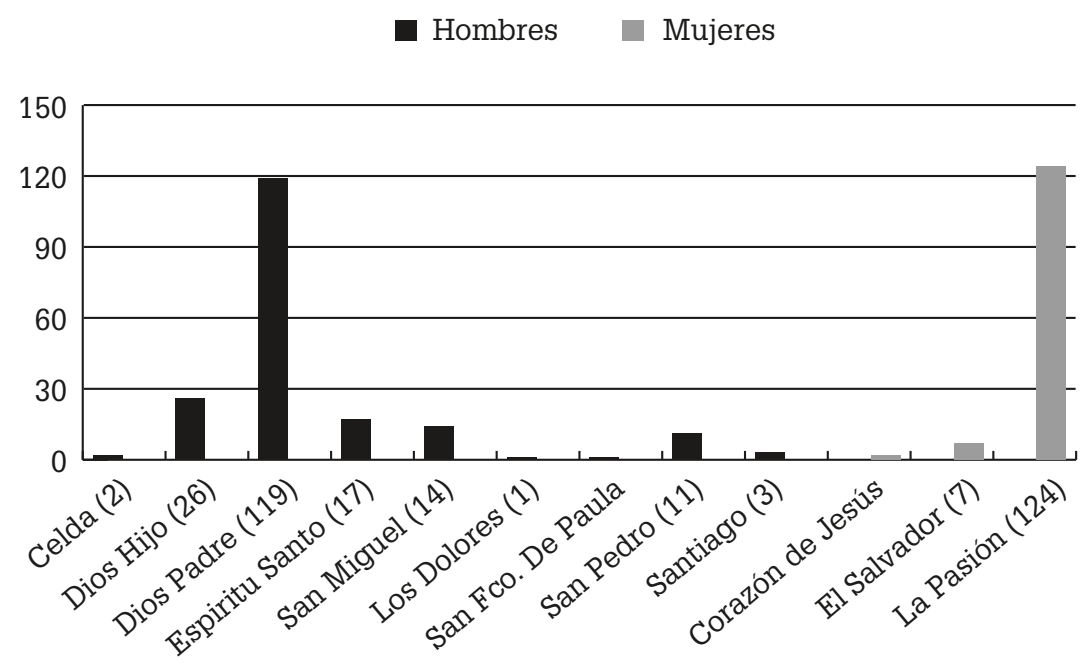

Fuente: AHJ, Libros de entradas y salidas, No. 21, 22 y 23 (1797-1798). Elaboración propia.

Una vez que se registraba el ingreso al hospital de los virulentos, la prioridad era recibir ayuda espiritual, de caridad y social, o recibir los santos óleos, independientemente de donde fueran asistidos, eso no interesaba ante la crisis. Por tal razón, es de suponer que las enfermerías debieron alterar sus protocolos y hacer caso omiso de lo que establecían las Constituciones de los Betlemitas, lo cual era justificado por la emergencia que representó la epidemia. Al desconocerse la etiología de la enfermedad y por las circunstancias del momento, no importaba la organización de las enfermerías ni la ubicación de las camas: la prioridad era brindar atención.

Sin embargo, al hacer un desglose de los espacios donde fueron confinados los virulentos, tanto hombres como mujeres, el 88.07\% quedaron registrados en salas para enfermos de fiebres y separados por sexo. De acuerdo con dato, para los varones los espacios de fiebres fueron Dios Padre (núm. 9), Dios Hijo (núm. 13) y Espíritu Santo (núm. 12), que entre las tres suman el $83.50 \%$ de los hombres enfermos de viruela.

En el resto de las salas de varones, las variaciones fueron las siguientes: entre los datos a resaltar tenemos que también se presentaron $18 \mathrm{ca}-$ 
sos de "virulentos reos" y 2 "virulentas reas"; de los hombres presos, 17 fueron consignados en la sala de Cirugía, es decir, Santiago y San Miguel (núm. 10). Es importante resaltar que la sala de San Miguel también fue el espacio destinado para resguardar a los presos involucrados en un caso judicial o aquellos enviados por alguna autoridad competente (posiblemente para curar alguna herida). Y en el caso de los religiosos enfermos de viruela, fueron recluidos en sus propias celdas, como el betlemita José y el hermano Domingo de la Santísima Trinidad. Con las mujeres virulentas, el $94.73 \%$ de las afectadas (126 casos) fueron ingresadas en sala de fiebres, principalmente La Pasión (núm. 30), con 124 enfermas, mientras que en Corazón de Jesús (núm. 29) se registraron 2 casos.

Interesa mostrar no solamente el impacto que la epidemia tuvo sobre el hospital, sino las problemáticas que presentaron dos espacios en la distribución de los enfermos por viruela: en hombres Dios Padre (núm. 9) y en mujeres La Pasión (núm. 30), situación que Oliver señaló en el análisis del recinto al mencionar "que la distribución dada a las salas tuvo como eje principal las enfermedades epidémicas" (1992, p. 262), lo cual el registro comprueba. Como podemos observar en el cuadro 4, en la sala de Dios Padre se registró, entre 1797 y 1799, un total de 164 ingresos; de éstos, 119 son de virulentos; en el caso de La Pasión, durante los tres años se registraron 133 ingresos, de éstos 124 son del mismo padecimiento. Entre las dos salas el estimado alcanzó el $74.31 \%$ de todos los enfermos de viruela ingresados al hospital. ${ }^{25}$

Con respecto a la distribución de los enfermos en las instalaciones, el 90\% de la atención se prestó en las cuatro salas más importantes ya mencionadas: dos de hombres (Dios Hijo y Espíritu Santo) y dos de mujeres (El Salvador y Corazón de Jesús), y para los virulentos la atención se brindó en dos enfermerías (Dios Padre y La Pasión), que funcionaron como los espacios que resguardaron a los convalecientes del padecimiento. En relación con el 10\% de los ingresos restantes, tenemos algunas consideraciones sólo para algunos casos (ver cuadro 6).

De estas causas que registran los libros del hospital, solamente se puede determinar la relación entre el padecimiento y las salas para el caso de los dementes, locos, furiosos y reos. Para los dementes, tanto hombres como mujeres, las salas donde se les recluyó fueron el patio de San Rafael, el patio de San Blas, el patio de San Gabriel y cuartos, que corresponden a las piezas destinadas para locos y delirantes y donde se y en 1799, 29 ingresos; en La Pasión hubo en 1797, 62 ingresos; en 1798, 71 ingresos, y en 1799 no se registró ninguno. 


\section{Cuadiro 6}

Otros padecimientos o causas registradas en los ingresos

del Hospital Real de San Miguel (1797-1799)

\begin{tabular}{|c|c|c|c|}
\hline No.* & $\begin{array}{l}\text { Salas y espacios } \\
\text { (hombre y mujer) }\end{array}$ & $\begin{array}{l}\text { Padecimiento o } \\
\text { causa }\end{array}$ & Cantidad \\
\hline 37 y 18 & $\begin{array}{l}\text { Patio de San Rafael, Patio de San } \\
\text { Blas, Patio de San Gabriel, piezas } \\
\text { para locas y delirio, etc. }\end{array}$ & $\begin{array}{l}\text { Dementes, locos y } \\
\text { furiosos }\end{array}$ & 67 \\
\hline 10 y 15 & San Miguel y Los Dolores & Reos & 300 \\
\hline 34 & Venerable P. Vetancourt & Parturientas & 19 \\
\hline 35 y 10 & $\begin{array}{l}\text { Sangre De Cristo, Santiago, San } \\
\text { Miguel, etc. }\end{array}$ & Lazarinos & 19 \\
\hline
\end{tabular}

* Número con el que se localizan en el plano de 1792.

Fuente: AHJ, Libros de entradas y salidas, No. 21, 22, 23 y 24 (1797-1799). Elaboración propia.

alojó el 83\% de los casos registrados con estos problemas; ${ }^{26}$ para el caso de los reos varones confinados por el tribunal de la Audiencia o alguna otra autoridad competente, del total de ingresos el $70 \%$ se recluyó en San Miguel, pensada para los enfermos de cirugía, y el 20\% en Los Dolores, para las unciones; en la sala del Venerable P. Vetancourt, destinada para parturientas, se registran 19 mujeres, sin embargo el registro solo señala sus características, calidad y rango de edad (entre los 15 y 62 años), ingresadas al hospital entre el 24 de julio de 1797 y el 10 de septiembre del mismo año, con un periodo de internamiento de 13 días por enferma. $\mathrm{El}$ hecho de haberse recluido durante un lapso que corresponde a tres meses consecutivos y de un solo año, y de forma casi seguida, lleva a pensar que probablemente no se trate de parturientas; sin embargo eso no se puede determinar. En cuanto a los lazarinos, su confinamiento se daba por lo regular en tres salas: para las mujeres, La Sangre de Cristo, y para los hombres, Santiago y San Miguel, entre otras. Con el resto de los enfermos y salas no podemos determinar la correspondencia entre lo que indica el registro hospitalario y lo que establecen las Constituciones o reglamentos internos.

26

Estos 67 casos corresponden en algunas ocasiones a enfermos que estuvieron recluidos cuando menos durante los tres años que contempla el presente trabajo. Por lo tanto, es necesario apuntar que se trata de 67 registros con estos males. 


\section{Consideraciones finales}

El panorama que se abordó sobre la distribución de los enfermos y las variaciones que presentaron los registros de ingresos, salidas y muertes de las diferentes salas del Hospital de San Miguel nos ayudó a reflexionar sobre las condiciones y capacidad que como instancia benefactora de los más necesitados caracterizó a la institución en un entorno de epidemias y diversos periodos de sobremortalidad, como la viruela de finales del siglo XVIII (1780, 1797-1798) y el bienio de 1785-1786, conocido como "los años del hambre", que llevaron a la construcción del nuevo Hospital Real de San Miguel. La institución respondía al concepto de caridad cristiana por el cual se fundó, la distribución de sus salas y su forma radiada permitían que los enfermos, locos, virulentos, lazarinos y todos los ingresados pudieran ser observados y también participar en las actividades espirituales, tal y como lo especificaban las Constituciones de la Orden.

Acerca de las salas, los datos sólo permitieron constatar las funciones que, para ciertos espacios, establecen las Constituciones de la Orden y la forma en que se distribuyeron los enfermos, según el plano de 1792. Destacan las enfermerías para fiebres (Dios Padre y La Pasión), y se demuestra al menos con estos dos espacios la puesta en práctica de los lineamientos de las Constituciones y lo establecido en el mismo plano como parte de las tareas asistenciales bajo la administración de los betlemitas.

El carácter humanitario y caritativo del hospital denota la dedicación y las virtudes de los religiosos de la orden de Belén, cuya labor entre la población se reflejó en la epidemia de 1797-1798. Virulentos que ingresaron al hospital y fueron recluidos en dos de sus salas, constata una sensibilidad en la forma de asistir a los enfermos. Si bien es cierto que ante el carácter agresivo de esta enfermedad había poco qué hacer, se destaca la distribución de los enfermos de viruela confinándolos en espacios separados para hacer frente al problema, paliar y reducir sus efectos. Fue un recinto que contó, por un lado, con las salas y camas necesarias para alojar y atender a los pobres, enfermos y a todos aquellos que necesitaban algún tipo de auxilio, y por el otro, con la labor desempeñada por los betlemitas, encargados de brindar la asistencia. Esto permite valorar las atenciones brindadas en las salas del hospital, el cuidado humano y la alimentación que los religiosos y demás personal diariamente suministraban a los enfermos.

\section{Siglas}

AHAG, Archivo Histórico de la Arquidiócesis de Guadalajara.

AHJ, Archivo Histórico de Jalisco, Guadalajara. 
BPEJ, ARAG, Biblioteca Pública del Estado de Jalisco, Archivo de la Real Audiencia de Guadalajara.

\section{Bibliografía.}

Argumaniz Tello, J. (2017)

Las epidemias y las acciones de las autoridades en Guadalajara, 17621825. Crisis de sobremortalidad, actores e instituciones. (Tesis doctoral en Ciencias Sociales. Universidad de Guadalajara).

Bentham, J. (1980)

Panóptico. México: Archivo General de la Nación.

Brun, E. (1982). "El Hospital Civil”, en J.M. Muriá et al. (comp.), Lecturas históricas de Jalisco. Antes de la Independencia, vol. II, Guadalajara: UNED, pp. 199-205.

Bustamante, M. (1982)

La viruela en México, desde su origen hasta su erradicación. En E. Florescano y E. Malvido (comp.), Ensayo sobre la historia de las epidemias en México. México: Instituto Mexicano del Seguro Social, pp. 67-92.

Cook, S. (1982)

La epidemia de viruela de 1797 en México. En E. Florescano y E. Malvido (comp.), Ensayo sobre la historia de las epidemias en México. México: Instituto Mexicano del Seguro Social, pp. 295-328.

Cooper, D. (1980)

Las epidemias en la ciudad de México, 1761-1813. México: Instituto Mexicano del Seguro Social.

Foucault, M. (1984)

Vigilar y castigar. Nacimiento de la prisión (trad. A. Garzón). México: Siglo XXI.

Gálvez Ruiz, M. (1996)

La conciencia regional en Guadalajara y el gobierno de los intendentes (1786-1800). Guadalajara: UNED.

Menéndez Valdés, J. (1980)

Descripción y censo general de la Intendencia de Guadalajara, 17891793, estudio preliminar de R. María Serrera. Guadalajara: UNED.

Muriel, J. (1990)

Hospitales de la Nueva España. México: Universidad Nacional Autónoma de México, 2 vol.

Navarro, L. (1982)

Fray Antonio Alcalde. En J.M. Muriá et al. (comp.), Lecturas históricas de Jalisco. Antes de la Independencia. Guadalajara: UNED, vol. II, pp. 207-212. 
Oliver Sánchez, L. (1992)

El Hospital Real de San Miguel de Belén, 1581-1802. Guadalajara: Universidad de Guadalajara.

Oliver Sánchez, L.(1992b)

Los betlemitas y la construcción de la nueva fábrica para el Hospital Real de San Miguel de Belén, Guadalajara, 1787-1794. Guadalajara: Universidad de Guadalajara.

Oliver Sánchez, L.(1997)

Mortalidad y los registros hospitalarios en Guadalajara durante el siglo XVII". En C. Becerra (comp.), Los occidentes de México (siglos XVI-XIX) El archivo: instrumento y vida de la investigación histórica. Guadalajara: Universidad de Guadalajara, pp. 453-466.

Oliver Sánchez, L.(2008)

La epidemia de viruela de 1830 en Guadalajara. Relaciones, Estudios de Historia y Sociedad, Epidemias de viruela en Nueva España y México, Siglos XVIII y XIX, vol. XXIX, 114, pp. 77-99.

Pérez Verdía, L. (1988)

Historia particular del estado de Jalisco, vol. I, Guadalajara: Universidad de Guadalajara.

Rosen, G. (1985)

De la policía médica a la medicina social. México: Siglo XXI.

Somolinos, G. (1982)

La viruela en la Nueva España.En E. Florescano y E. Malvido (coord.), Ensayos sobre la historia de las epidemias en México, México: Instituto Mexicano del Seguro Social, pp. 237-248.

Serrera, R. (1991)

Guadalajara ganadera. Estudio regional novohispano (1760-1805). Guadalajara: Ayuntamiento de Guadalajara.

Van Young, E. (1989)

La ciudad y el campo en el México del siglo XVIII. La economía rural de la región de Guadalajara, 1675-1820. México: Fondo de Cultura Económica. 